\title{
Cardiovascular Diseases, Depression Disorders and Potential Effects of Omega-3 Fatty Acids
}

\section{J. TREBATICKÁ ${ }^{1}$, A. DUKÁT ${ }^{2}$, Z. ĎURAČKOVÁ ${ }^{3}$, J. MUCHOVÁ $^{3}$}

${ }^{1}$ Department of Child and Adolescent Psychiatry, Faculty of Medicine, Comenius University and Child University Hospital, Bratislava, Slovakia, ${ }^{2}$ Second Department of Internal Medicine, Faculty of Medicine, Comenius University and University Hospital, Bratislava, Slovakia, ${ }^{3}$ Institute of Medical Chemistry, Biochemistry and Clinical Biochemistry, Faculty of Medicine, Comenius University, Bratislava, Slovakia

Received July 8, 2016

Accepted November 25, 2016

On-line February 28, 2017

\section{Summary}

Cardiovascular disease (CVD) and depressive disorders (DD) are two of the most prevalent health problems in the world. Although CVD and depression have different origin, they share some common pathophysiological characteristics and risk factors, such as the increased production of proinflammatory cytokines, endothelial dysfunction, blood flow abnormalities, decreased glucose metabolism, elevated plasma homocysteine levels, oxidative stress and disorder in vitamin D metabolism. Current findings confirm the common underlying factors for both pathologies, which are related to dramatic dietary changes in the mid-19th century. By changing dietary ratio of omega- 6 to omega-3 fatty acids from $1: 1$ to $15-20: 1$ some changes in metabolism were induced, such as increased pro-inflammatory mediators and modulations of different signaling pathways following pathophysiological response related to both, cardiovascular diseases and depressive disorders.

\section{Key words}

Cardiovascular diseases - Depressive disorders - Omega-3 fatty acids • Docosahexaenoic acid • Eicosapentaenoic acid

\section{Corresponding author}

J. Muchová, Institute of Medical Chemistry, Biochemistry and Clinical Biochemistry, Faculty of Medicine, Comenius University, Sasinkova 2, 81372 Bratislava, Slovakia. E-mail: jana.muchova@fmed.uniba.sk

\section{Introduction}

Cardiovascular disease (CVD) and depressive disorders (DD) are two of the most prevalent health problems in the world. Ten-fold increase in CVD and depressive disorders in the contrary to two-fold increase in cancer over the last $150-180$ years in western countries was observed. Although CVD and depression are very different pathologies, they share some common pathophysiological characteristics and risk factors, such as the increased production of pro-inflammatory cytokines, endothelial dysfunction, blood flow abnormalities, decreased glucose metabolism, elevated plasma homocysteine levels and disorder in vitamin D metabolism (Grosso 2014). Several common pathophysiological features underline the importance of environmental factors in mental disorders and CVD. One of the factors that could explain the parallels in these diseases could be related to a dramatic change in dietary habits and intake of polyunsaturated fatty acids (PUFAs, polyunsaturated fatty acids) in favor of saturated fatty acids (FA) and to the increase of the ratio of omega-6 FA to omega-3 FA in the last 150 to 180 years (Simopoulos 2002).

Substantial changes in dietary habits have been accompanied by the increased prevalence of both, CVD and depressive disorders.

The main source of food for our ancestors before 


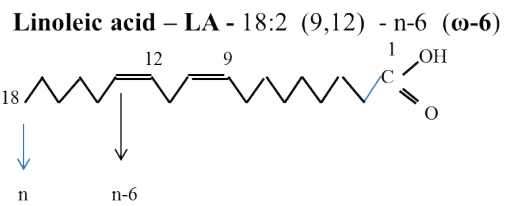

Linolenic acid - ALA (alpha-linolenic acid) - 18:3 (9,12,15) - n-3 ( $(\omega-3)$

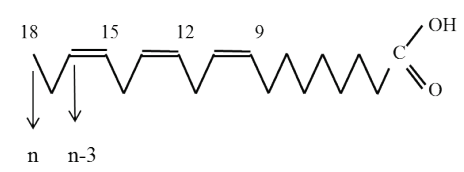

Fig. 1. Essential fatty acids.

the agricultural and industrial revolution in the mid-19th century was the lean meat, fish, green leafy plants, fruits and various berries. Their diet contained only few cereals and saccharides and honey as a sweetener. For this type of diet our genetic material has been furnished. However, especially in the last 150 years, there was a dramatic shift from the food to which the human body was genetically programmed and adapted for millennia. After industrial and agricultural revolution, people have changed their dietary habits, cereals became a central part of the diet, composition of fats was considerably changed, intake of omega- 6 fatty acids was increased and the ratio of omega- 6 fatty acids to omega-3 fatty acids has been changed from the original $1: 1$ to $15-20: 1$. Unlike our ancestors, when $90 \%$ of the diet consisted of a very wide range of different plants, today the main components of food are cereal grains, in particular wheat, maize and rice. These dietary changes have resulted in the development of several diseases, such as CVD, diabetes mellitus and mental disorders. Several epidemiological and experimental studies have highlighted the potential role of omega-3 fatty acids in the prevention and treatment of CVD (Sinclair 1956, Tavazzi et al. 2008, Oikawa et al. 2009, di Minno et al. 2010, Delgado-Lista et al. 2012) as well as psychiatric disorders, such as depressive disorders (Lin and Su 2007, Sublette et al. 2011, Lin et al. 2012), attention deficit hyperactivity disease (ADHD) (Gow et al. 2015, Patrick and Ames 2015) and schizophrenia (Patrick and Ames 2015, Buol and Altamura 2015).

Fatty acids (FA) are monocarboxylic acids mainly bound in lipids with number of carbon atoms exceeding 10. Fatty acids can be saturated or unsaturated. Unsaturated FA containing unsaturated (double) bonds (polyunsaturated fatty acids, PUFAs) are divided into several groups according to the position of the first double bond from so called " $n$ " end ( $\omega$, omega end) of the FA chain (the last carbon from the carboxyl group,

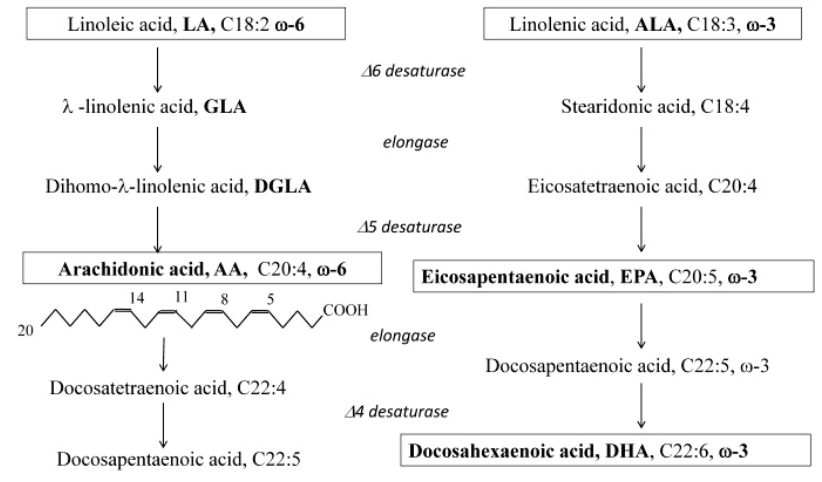

Fig. 2. Polyunsaturated fatty acids synthesis from linoleic acid and linolenic acid.

- $\mathrm{COOH}$ ): i) omega-3 FA (e.g. alpha linolenic acid, ALA, C18:3; eicosapentaenoic acid, EPA, C20:5; docosahexaenoic acid, DHA, C22:6), ii) omega-6 FA (e.g. linoleic acid, LA, C18:2; arachidonic acid, AA, C20:4), iii) omega-9 FA (oleic acid C18:1). Essential FAs which the body can not synthesize, and must be supplied in the diet are listed in Figure 1.

Non-essential FAs and other lipids can either enter the body exogenously as a component of our food, or be synthesized endogenously in small amounts in cells. Circulating plasma FAs come mainly from triacylglycerols (TAG) after their hydrolysis by lipases. FA concentration in plasma is the result of two opposing processes: FAs supply from food or their endogenous synthesis and from the use of FAs. FAs are used for energy production, incorporation into cell membranes and storage.

Essential FAs obtained from dietary sources of triacylglycerols include:

1) LA (omega-6 FA) is present mostly in vegetable oils such as sunflower, canola, hemp, soybean and corn oil, or borage oil and evening primrose, or safflower oil. Less LA is in the flax seed oil. Omega-6 FA is present also in tofu, almonds, walnuts, blackcurrant seeds. In addition to the essential LA, also AA, belongs to the omega- 6 FA, which in the human body may be synthesized in tiny amounts from LA by the elongation.

2) ALA (omega-3 fatty acid) mainly found in fatty fish such as salmon, tuna, herring, mackerel, anchovies or sardines, but also in the seeds of flax, hemp and the walnuts and in certain vegetables such as kale, spinach, salads. Small amount of ALA can get in the body by consumed chicken and beef. The most important omega-3 fatty acids include EPA, and the most unsaturated FA DHA, which in the body may also be synthesized in tiny amounts from ALA with the same 
desaturation and elongation enzymes as the AA (Fig. 2).

In human organism the primary site of synthesis of AA and DHA from LA and ALA required for the brain, is the liver. The synthesis is carried out in the endoplasmic reticulum and is finalized in the peroxisomes of cells. However, in contrast to other mammals, production of DHA from ALA is very slow in human and represents only about $0.5 \%$ of the total ALA obtained from food ( 1 to $1.5 \mathrm{~g}$ /day). Synthesis of DHA requires the same desaturases as the synthesis of AA, which are in constant mutual competitions (Salem et al. 1999).
Polyunsaturated fatty acids are transferred from the food to the liver, where AA and DHA are synthesized from the LA and ALA, and are stored in very low density lipoproteins (VLDL) in the form of triacylglycerols (TAG). From TAG they are released by lipases. Circulating fatty acids AA and DHA are transported by blood bound to albumin or to glycerophospholipids of lipoproteins. They cross the blood-brain barrier (BBB) of nerve cells by passive diffusion, using various protein transporters and receptors (Fig. 3).

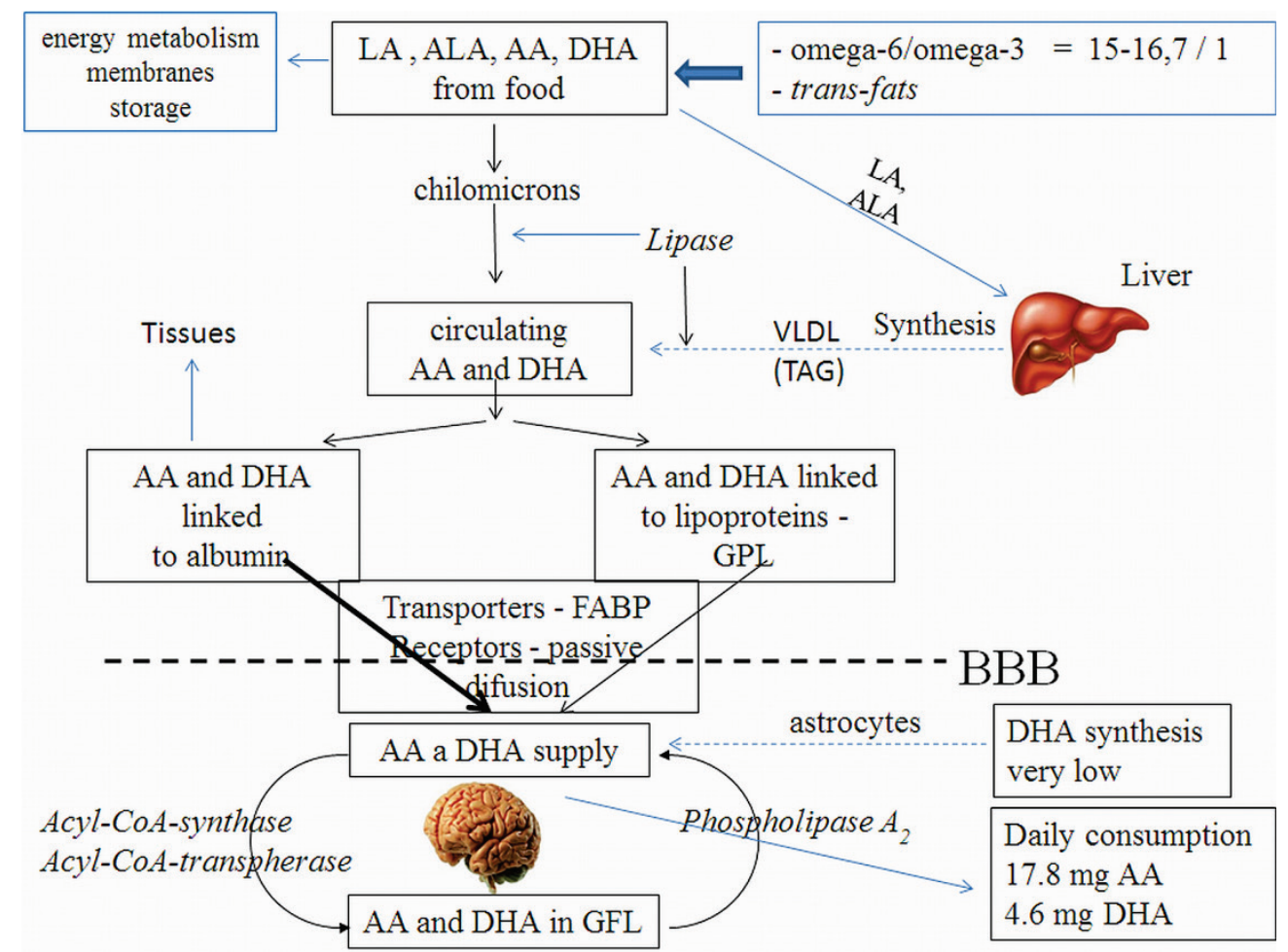

Fig. 3. Fatty acid metabolism. AA - arachidonic acid, BBB - blood brain barrier, DHA - docosahexanoic acid, LA - linoleic acid, ALA - alpha linolenic acid, FABP - fatty acid binding protein, GFL - glycerophospholipid, TAG - triacylglycerol, VLDL - very low density lipoprotein.

Brain has a different lipid profile than blood. Also distribution of FA in brain is different from other organs and blood. The brain is relatively pure in linoleic and alpha-linolenic acid but it contains more saturated 18-carbon acids and less 16-carbon acids, compared to other tissues. Of the omega-3 fatty acids, DHA is mostly present in the gray matter in the phosphatidylethanolamine and phosphatidylserine (less in phosphatidylcholine) and sparsely in myelin. However, the EPA is present only in trace.

DHA can be synthesized also in the brain, but the speed of its synthesis compared to the liver is very low. Incorporation of DHA/EPA into glycerophospholipids of the cell membrane competes with the incorporation of AA. DHA in cell membranes of the brain affects many properties of the membrane such as the thickness of bi-layer, the free volume of the acyl chains, phase transition temperature, the lateral separation of membrane lipids in the DHA-rich/cholesterol-poor, and vice versa DHA-poor/cholesterol-rich regions and the formation of lipid microdomains (rafts) responsible for modulation and integration of signal transduction (Farooqui et al. 2007, Farooqui 2009, Ma et al. 2004). DHA in the membrane of nerve cells affects its fluidity, thereby affecting the activity of integral membrane proteins, ion channels and neurotransmitter receptors. 
However, higher doses of omega-3 FA can exhibit undesirable side effects including increased risk of bleeding, e.g. in the gastrointestinal tract or in the brain (stroke). Gastrointestinal discomfort may include loose stools, diarrhea, nausea, vomiting and loss of appetite. Some symptoms are removed when the FA are consumed with the food. Patients with the planned operation are advised to avoid consumption of polyunsaturated FA 3-7 days before surgery. Chronic administration of FA can cause a deficiency of vitamin $\mathrm{E}$, so some clinicians recommend the additional administration of vitamin $\mathrm{E}$, especially at higher doses of polyunsaturated FA. However, the observed side effects are usually seen in adults, therefore profile of potential side effects in children can be different from that in adults (Gow and Hibbeln 2014).

\section{Cardiovascular disease (CVD)/Coronary heart} diseases including heart attack stroke and heart failure is the leading cause of death and hospitalization in the world. It is considered the most significant health problem worldwide (Joyn et al. 2003). CVD causes more than half of all deaths across the European Region (WHO, 2007). Cardiovascular disease causes more deaths among Europeans than any other diseases and in many countries still causes more than twice as many deaths as cancer (Nichols et al. 2014).

The major cause of CVD is atherosclerosis. It is a chronic inflammatory disorder that is developed slowly over many years. The main risk factors of atherosclerosis can be divided into few groups: (1) non modifiable (age, ethnicity, gender, genetics), (2) modifiable by lifestyle (diet, obesity which initiates metabolic syndrome and insulin resistance, smoking leading to the reduction of glutathione peroxidase activity, physical inactivity), (3) modifiable by drugs (dyslipidemia with high level of low density lipoproteins (LDL), hypertension with increased production of angiotensin II), (4) nontraditional risk factors (lipoprotein A, homocysteine, infections, systemic lupus erythematosus).

These risk factors, namely dyslipidemia, hypertension and smoking unite other mechanisms including oxidation and inflammatory processes in the artery wall resulting in rise of characteristic fatty-fibrous lesions. The opinion on the role of oxidative stress in human atherogenesis is still unclear, because clinical trials using antioxidants showed predominantly negative results (Scott 2004). However, in the large prospective study the benefits of traditional Mediterranean diet with fish and olives showed reduced oxidative stress suggesting that the problem is more complex and diverse diet provides a mixture of necessary antioxidants in comparison to single one (Trichopoulou et al. 2003).

Inflammation represented by its general marker, C-reactive protein (CRP), is one of central processes in atherogenesis. CRP is produced by the liver in response to pro-inflammatory cytokines such IL-6. It binds oxidized LDL and is present in atherogenic lesions where it may act as a chemoattractant and be involved in the expression of adhesion molecules (Mosca 2002).

Inflammatory mechanisms couple dyslipidemia to atherogenesis. Leukocyte recruitment and expression of pro-inflammatory cytokines characterize early state of atherogenesis. Inflammatory pathways promote thrombosis, a late and serious complication of atherosclerosis resulting in myocardial infarction and strokes. The recognition of the role of inflammation in atherosclerosis, identification of triggers for inflammation allows to understand the clinical benefits of lipidlowering therapies and possible new therapeutic targets and approaches. Usually drugs used to treat atherosclerosis like aspirin, statins, peroxisome proliferator-activated receptors alpha agonists, angiotensin II signalling inhibitors, exhibit anti-inflammatory properties and calcium channel blockers (Libby 2002).

The first information about the relation between essential fatty acids and cardiovascular diseases including atherosclerosis was published by Sinclair (1956) after his observations from his first visit of Eskimos in Greenland in 1944. He observed that traditional diet of Inuit population is rich in seal and fish with high contents of omega-3 fatty acids exhibiting antithrombotic effect, which could be the reason for the rare occurrence of ischemic heart disease in Greenland Eskimos (Puri 2008). Mizushima et al. (1997) reported results from Japanese epidemiological studies which confirmed a dose-response relationship between the frequency of weekly fish consumption and reduced CVD risk factors (e.g. obesity, hypertension, glycohemoglobin, ST-T segment change on the electrocardiograms) and reduced incidence of cerebro-thrombic diseases.

Over the past 20 years, there has been a marked increase in the scientific investigation and public interest in omega-3 and omega-6 FA and their impact on personal health. Several studies have shown an inverse association between fish consumption and risk of coronary heart disease including sudden cardiac death, like JELIS study 
(Oikawa et al. 2009), DART study included men recovering from acute myocardial infarction (Burr et al. 2005) or GISSI preventive study with survivors of myocardial infarction (Tavazzi et al. 2008). Also recent reviews have reported beneficial effects of omega-3 FA in preventing cardiovascular and coronary events and cardiac death (Delgado-Lista et al. 2012) and especially in triacylglycerol level decreasing activity (di Minno et al. 2010) and increasing the clearance of plasma triacylglycerols (Harris et al. 2008). However, some studies have not found any relation between fish consumption or omega-3 FA supplementation and mortality among men with angina (DART-2 trial) (Burr et al. 2003). Omega-3 FA in ten randomized controlled trials did not reduce the secondary risk of sudden cardiac death in patients with CVD (Chen et al. 2011).

These discrepancies can be caused by different design of trials, heterogeneity of subjects included into study according to the primary prevention category or group with high risk for CVD, time of duration, different doses of supplemented omega-3 FA and also different DHA and EPA ratio in the diet (Nestel et al. 2015).

It is supposed that omega-3 FA can be cardioprotective due to multiple mechanisms (Jain et al. 2015):

The benefits of fish oils were originally thought to be due to their antithrombotic effects, but results indicated antiarrhythmic effect as a predominant effect (Din et al. 2004, Rizos and Elisaf 2013).

Effects of omega-3 FA:

1) Antiarrhythmic effect of omega-3 FA - through stabilization of electrical activity of cardiac myocytes by sarcolemmal ion (sodium, potassium and calcium) channel inhibitions resulting in a prolonged relative refractory period. Moreover, omega-3 FA alter the membrane fluidity and thus influencing the ion transport. However, the protection of atrial fibrillation is limited to patients with structural changes of the heart such as heart failure but not with lone atrial fibrillation (Sakabe et al. 2007). Also post-operative atrial fibrillation was not considerably influenced (Mozaffarian et al. 2012).

2) Antithrombic effect was first determined for EPA - it reduces platelet adhesion and reactivity leading to increased bleeding time and namely, it inhibits the synthesis of thromboxane A2, which causes platelet aggregation and vasoconstriction (Connor et al. 1997).

3) Antiinflammatory effect - omega-3 FA are in competition with arachidonic acid, a precursor for the synthesis of pro-inflammatory eicosanoids (Rees et al. 2006). On the other hand, EPA is the substrate for synthesis of anti-atherogenic eicosanoids (Calder 2009).

4) Inhibition of atherosclerotic plague formation by EPA and DHA - through the reduction of macrophages in atherosclerotic plaque (Plutzky 1999) and reduction of total volume of the atherosclerotic plaque (Thies et al. 2003) and decreasing of plateletderived growth factor production, a key chemoattractant and mitogen for smooth muscle cells and macrophages.

5) Endothelial function influenced by EPA - through increasing the bioavailability of nitric oxide after the inhibition of superoxide production by neutrophils resulting in increased vasodilatory effect. However, no effects of omega-3 FA on endothelial vasomotor function, tissue plasminogen activator (t-PA) or cluster of differentiation 40 (CD40) and its ligand CD40L was observed in patients with a previous myocardial infarction (Din et al. 2013).

6) Antiatherogenic effect of omega-3 FA on lipid risk factors - high EPA/DHA ratio contributed to a greater decreasing tendency in triacylglycerol levels through the inhibition of their synthesis in liver, however, no marked changes in total cholesterol was recorded in diabetic patients (Chen et al. 2015). In normolipidemic or borderline hyperlipidemic individuals the reduction in circulating triacylglycerols (9-26\%) was demonstrated in trials where $\geq 4 \mathrm{~g}$ /day of omega-3 FA from food were consumed, while a $4-51 \%$ reduction was found in trials where 1-5 g/day of EPA and/or DHA was consumed in supplements. In studies directly comparing EPA and DHA, DHA caused reduction of triacylglycerols more effectively than EPA (-22.4\% vs. $-15.6 \%)$ and elevation of HDL cholesterol $(+7.3 \%$ vs. $1.4 \%$ for EPA). However, also elevation of LDL cholesterol after DHA-containing but not EPA-containing supplements or therapies were observed (Leslie et al. 2015). Omega-3 FA can also markedly reduce atherogenic postprandial lipemia (Harris 2008).

7) Blood flow abnormalities can be modulated by omega-3 FA - omega-3 FA increased forearm blood flow in people with chronic heart failure or in smokers (Din et al. 2013). Fish oil appeared to have more significant effects in younger men, compared to older men. More information is needed in this research area.

Fourty-two years after the publication of Hugh Sinclair's research on the essential fatty acids and atherosclerosis in Lancet, another paper in Lancet was published by Joseph Hibbeln (1998), who in his 
epidemiological study found a significant negative association between the annual prevalence of major depression and apparent fish consumption (Puri 2008). Several studies have reported reduced level of omega-3 FA in erythrocyte membranes (Edwards et al. 1998) in patients with depression compared to healthy control. Seasonal variation in polyunsaturated fatty acids, particularly EPA was related to a seasonal variation in violent suicide and serotonergic markers of violent suicide (de Vriese et al. 2004). The first therapeutical use of EPA for the treatment of depression was published by Puri et al. (2001).

\section{Depressive disorders (DD)}

The increased incidence of DD in people of western countries has been associated with drastic changes in dietary habits over the century, in which the consumption of omega-3 fatty acids in the form of fish, grain and vegetables has been replaced by the omega- 6 FA from cereal oils. The ratio of omega-3 FA to omega-6 FA in the diet has shifted from 1:1 to $1: 15$ and this switch has coincided with a strong rise in the rates of depression in recent decades. From this follows the hypothesis that omega-3 FA supplementation could be one approach for treating depression and other mood disorders (Caballero-Martínez 2014, Lopresti et al. 2015).

Epidemiological cross-sectional and prospective cohort studies of efficacy of omega-3 FA consumption against depression showed conflicting results (Grosso et al. 2014). No association between the dietary intake of omega-3 FA and depressed mood, major depressive episodes, or suicides were observed in men in Finland (Hakkarainen et al. 2004), Australia (Jacka et al. 2004) and Greece (Kyrozis et al. 2009). On the other hand, potential protective effect of fish consumption rather than omega-3 FA supplementation was found in Fishermen study (Suominen-Taipale et al. 2010). In Danish women during 1 year postpartum a negative association between fish consumption, but not omega-3 FA intake, and postpartum depression was observed (Strøm et al. 2009). In two cohort studies, French study SUVLMAX and SUN study, individuals consuming fatty fish or omega-3 FA higher than $0.1 \%$ of energy intake during 2 years had a significantly lower risk for any depressive episode (Astorg et al. 2008, Sanchez-Villegas et al. 2007).

Similarly, also experimental studies have reported some controversial outputs following from several meta-analyses. Despite the reported general positive effects of omega-3 FA intake on improvement of depressive symptoms (Freeman et al. 2006, Lin and Su 2007), some other systemic reviews presented no effect of omega-3 FA on depressive symptoms (Appleton et al. 2006, Rogers et al. 2008).

This discrepancy between results from different studies can be attributed to significant heterogeneity among studies including different protocol and design of the study, duration of supplementation, doses of omega-3 FA, homogeneity of patients (the pathophysiology of major depression can be different than comorbid depression). For example, our results indicate that patients with depressive episode (according to International Classification of Diseases, ICD-10, F32) are more sensitive to omega-3 FA treatment compared to mixed anxiety and depressive disorder (F41.2) (Trebatická et al. 2016). Also a source of omega-3 FA, their form of application (diet, emulsion, capsules) or especially EPA/DHA ratio can influence final results. Results from recent meta-analyses suggest that EPA rather than DHA had positive effects on depressive symptoms as adjuvant therapy compared to mono-therapy (Grosso et al. 2014). Supplements containing minimally $60 \%$ of EPA of total omega-3 FA at dose 200-2,200 mg/day of EPA were effective (Sublette et al. 2011). More unrecognized situation is in antidepressant effect of omega-3 FA in children and adolescents (Lopresti 2015). Only two reviewed studies (Nemets et al. 2006, McNamara et al. 2014) evaluated an impact of omega-3 FA on depressive symptoms. Also our results (Trebatická et al. 2016) suggest a significant effect of daily doses of fish oil emulsion providing $2.4 \mathrm{~g}$ of total omega-3 FA (1 g EPA and $0.750 \mathrm{~g}$ DHA, EPA:DHA ratio $=1.33: 1$ ) on symptoms determined with CDI score. More sensitive were patients with depressive episodes compared to mixed anxiety and depression.

Hypothesized mechanism of omega-3 FA action in brain function (Liu et al. 2015):

1) Omega-3 FA and signaling in brain - animal studies indicate that omega-3 FA influenced dopaminergic system. For example, in rats fed with omega-3 FA deficient diets lower levels of dopamine, D2 receptors, D2 receptor $\mathrm{mRNA}$ and dopaminergic presynaptic vesicles and increased breakdown of dopamine in the prefrontal cortex (Zimmer et al. 1998, 2000) and decreased tyrosine hydroxylase, the rate limiting enzyme in dopamine synthesis (Kuperstein et al. 2008) were observed. Conversely, high-omega-3 FA diet exhibits opposite relations involving decreasing 
monoamine oxidase $\mathrm{B}$ activity in prefrontal cortex (Chalon et al. 1998). Omega-3 FA can interact with the serotonine (5-hydroxytryptamin; 5-HT). Rats with low level of DHA had lower level of 5-HT and its turnover in frontal cortex and higher density of hippocampal 5-HT2A receptors (Levant et al. 2008). Conversely, in adult male mice under chronic mild stress increased 5-HT level was recorded after omega-3 FA supplementation (Vancassel et al. 2008).

Also some other signaling pathways can be modulated by omega-3 FA, like phosphoinositide pathway through modulation of phospholipase $\mathrm{C}$ and protein kinase $\mathrm{C}$ or calmodulin-dependent protein kinase involved in $\mathrm{Ca}^{2+}$ dependent release of neurotransmitters from synaptic vesicles and $\mathrm{Ca}^{2+}$-ATPase in neuronal membranes, which is inhibited by DHA and EPA (Kearns and Haag 2002).

In the recent years the role of increased activity of glutamate receptor and N-methyl-D-aspartate (NMDA) receptor agonism was studied in relation to functional and structural plasticity in the adult brain. An increased activity of glutamatergic system and NMDA receptor agonism is associated with depressed mood (Latour et al. 2013).

2) Omega-3 FA and neuroinflammation - polyunsaturated fatty acids during their catabolism are substrates for few enzymes when different eicosanoids and docosanoids are formed (Fig. 7). Arachidonic acid (AA) is released from phospholipids through the action of phospholipase A2 and then is metabolized by cyclooxygenase (COX), lipoxygenase (LOX) or cytochrome P450. COXs form prostaglandins (PG) and thromboxanes (TBx), LOXs form leukotriens (LT) and cytochrome P450s form hydroxyeicosatetraenoic and epoxyeicosatrienoic acids. DHA and EPA formed from alpha-linolenic acid (ALA) are in competition with AA formed from linoleic acid (LA) and their incorporation in cell membrane decreases AA contents and by this way availability of substrate for synthesis of pro-inflammatory eicosanoids, like LTB4, TBx4. On the other hand, anti-inflammatory eicosanoids, like PGF3 and PGF3a are formed from EPA (Fig. 8).

In depressive patients increased production (during an acute phase response) of pro-inflammatory cytokines such as IL-1 beta, IL-6, IL-12, THF-alpha was observed (Mamalakis et al. 2004, Wichers and Maes 2002). Administration of omega-3 FA to healthy human caused decreased production of tumor necrosis factor (TNF) alpha, IL-1 beta and IL-6, but not in all studies
(Dowlati et al. 2010). However, the question is as to whether increased level of omega-3 FA in plasma is related to reduce inflammatory processes in the brain? In recent paper by Calder (2013) a reduction of expression of TNF alpha, IL-6, NO synthase and COX-2 and upregulation of heme oxygenase-1 in BV-2 microglia was published. However, some other results indicate that these associations are dose- and time of FA intake-dependent (Lu et al. 2010).

3) Omega-3 FA and neuroprotection - in the contrast to pro-inflammatory eicosanoids derived from omega-6 FA, docosanoids derived from unesterified DHA exhibit stereospecific anti-inflammatory effects also in brain. The three known classes formed from controlled oxidative break-down of DHA or EPA with lipoxygenases within the membrane are resolvins, docosatrienes and protectins (Farooqui et al. 2007, Serhan 2005). Resolvins are divided into two groups, D-series and E-series; depending on the FA they are derived from: either from DHA or EPA, respectively (Orr et al. 2013). Resolvin E1 has been reported to reduce inflammation by suppressing the activation of transcription factor NFאB (Faooqui et al. 2007). Neuroprotectins are able positively affect neuronal survival through altering of pro- or anti-apoptic gene expression (Liu et al. 2015) and resolvins protect the brain from ischemia (Marchesselli et al. 2003). DHA depletion has been shown to result in decreased brainderived neurotrophic factor in rodents and increase of neuronal hippocampal cell death through apoptosis (Akbar et al. 2005).

4) Omega-3 FA in regulation of brain energy - DHA has been also identified as an important regulator of brain energy metabolism (Liu et al. 2015) having effects on both glucose uptake and on the density of glucose transporter-1 in endothelial cell culture and in cerebral cortex from rat brain (Pifferi et al. 2007). Neuroimaging in humans with positron emission tomography has found correlations between plasma fatty acid levels and cerebral metabolic rates for glucose in specific brain regions (Sublette et al. 2009).

5) Hypoperfusion in the limbic system and prefrontal cortex in depressed patients was reported using a pixel-by-pixel basis photon emission computed tomography (SPECT) method (Ito et al. 1996). Using single SPECT method imaging in suicide patients reduction of regional cerebral blood flow was detected in the medial prefrontal cortex (Willeumier et al. 2011). The benefit of omega-3 FA could be attributed also to 
alteration in blood flow to the brain (Stahl et al. 2008).

\section{Two-way relationship between depression and cardiovascular disease}

Several epidemiological, retrospective or review studies have suggested an association between mood state (depression) and cardiovascular diseases (Joynt et al. 2004, Mosovich et al. 2008, Calder and Yaqoop 2009, Hare et al. 2014). CVD and depression are currently the two most common causes of disability in high-income countries. Although manifestation of these two diseases is different, their relation has bi-directional character. Their prevalence is similar and is greater than average in other medical conditions such as cancer, erectile dysfunction or cerebrovascular diseases (Grippo and Johnson 2002). CVD is the leading cause of death and disability in developed world. Depression is a leading cause of disability worldwide and major determinant of patient adherence to appropriate medical and life-style strategies (Hare et al. 2014).

Depression has been cited as a significant risk factor for recurrent cardiac events and can heighten its severity in patients with established cardiovascular disease. $20-50 \%$ of patients who die from myocardial infarction are thought to be significantly depressed prior to the infarction (Grippo and Johnson 2002).
On the other hand, CVD may induce depression. Several studies have found increased rates of depression following a stroke event. The most common form of depression experienced after acute coronary event is an "adjustment" disorder with depressed mood when marked reduction in depression of cardiac patients over time has been seen. However, in patients after the stroke $27 \%$ had major depression and 14-18\% minor depression (Hare et al. 2014). Several previous papers suggest that depression can influence cardiovascular function, and vice versa cardiovascular diseases also influence affective states. The review of pathophysiological characteristics of CVD and depression is given in Figure 4.

CVD and depression might share a common underlying cause, like neurohormonal activation, rhythm disturbance, inflammation and hypercoagulability, which may initiate both pathological conditions (Fig. 4) (Joynt et al. 2004). A number of factors increase an individual's risk for CVD, including smoking, hypertension, diabetes, dyslipidemia, metabolic syndrome, stress or obesity and also for depression including presence of previous depression, depression in family history, difficult life events, substance use disorder, chronic somatic disorder, no relationships, no family, poor social life, loss of mother before 11 years of age, divorce, being single, widow/er, lower socioeconomic status.

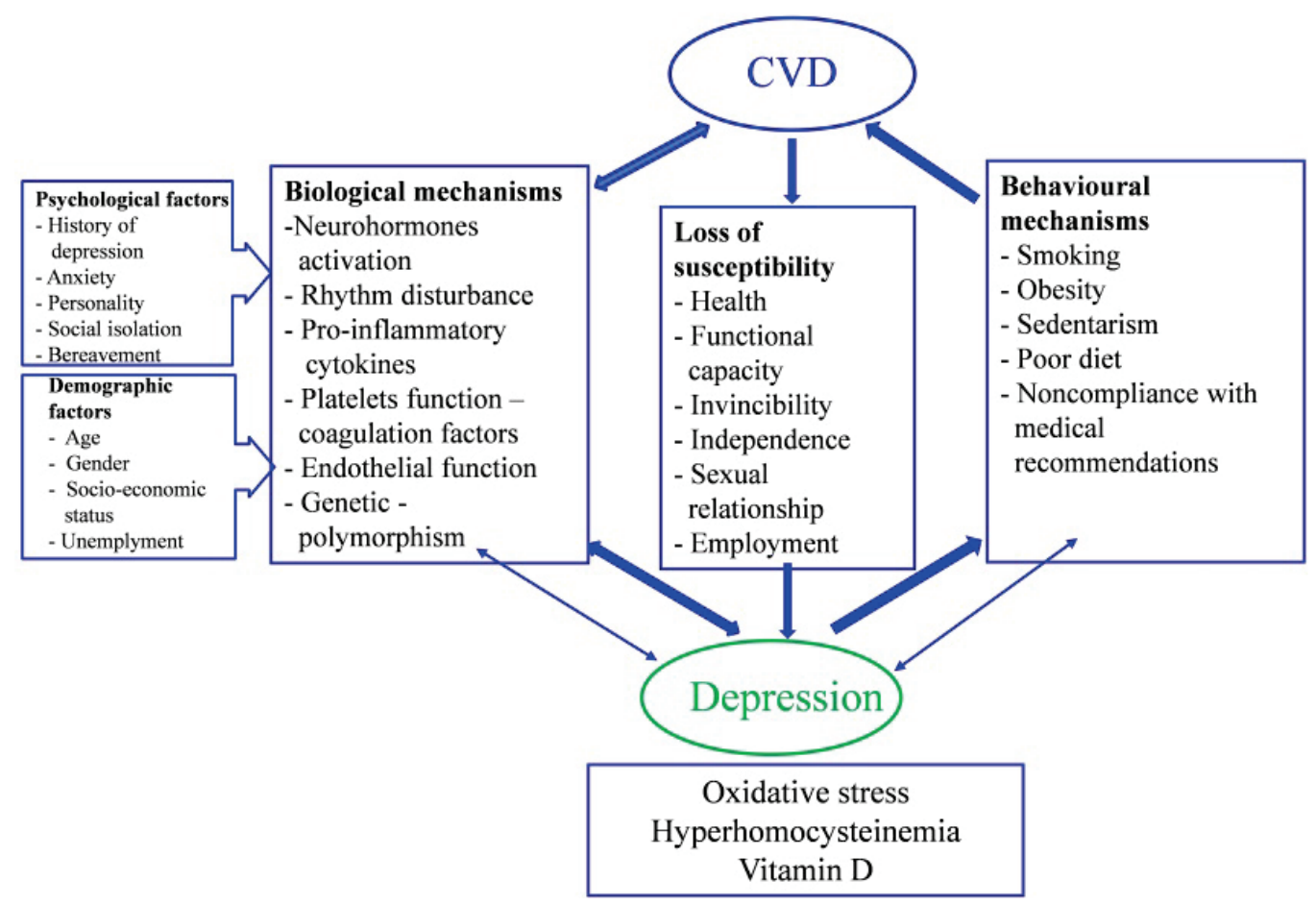

Fig. 4. Pathophysiological characteristics of cardiovascular diseases and depression disorders. CVD - cardiovascular disease. 
Also some „novel“ risk factors underlying the mutual association between CVD and psychiatric disorders, such as oxidative stress, homocysteine or vitamin D have been identified (Fig. 4).

Oxidative stress (more precisely referred to as redox stress) as a disturbance in the pro-oxidant/antioxidant balance in favor of the former, is leading to potential damage (Duračková 2014). Oxidative stress at low level exhibits some biomodulating activities in signaling and functioning of cells relevant to pathogenesis of CVD and psychiatric disorders including the effect on cell proliferation, apoptosis, survival or generally on the cell fate (Duračková 2010). However, at high level oxidative stress can be deleterious and may be intrinsically involved in the shared disposition for both CVD and psychiatric disorder. It is supposed that through FA peroxidation oxidative stress could be a mediator in the brain (modest antioxidant defense and highly oxidizable substrate - lipids) and cardiovascular system (atherosclerosis, diabetes mellitus or insulin resistance development, increased mitochondrial production of ROS, inverse correlations between antioxidant enzymes and CVD). Oxidative stress mediated structural and functional effects on FA metabolism including FA peroxidation products may underlie the clinical overlap between CVD risk factors and psychiatric disorders through decreasing of long-chain PUFAs, omega-3/ omega-6 FA ratio, changing activities of desaturases and increasing pro-inflammatory eicosanoids (Assies et al. 2014).

However, the final effect of oxidative stress on fate of cells, organs or organism is dependent not only on pro-oxidant/antioxidant balance, but also on the type of oxidants, type of missing antioxidants, and on the duration and the intensity of oxidative stress (Ďuračková 2010). For example, oxidative stress may be an early causative factor in CVD pathology rather than a late consequence. McCarthy (2014) discussed results of Assies et al. (2014) and concluded that authors explained how oxidative stress may impact simultaneously upon cardiac, metabolic and mental health. They showed biochemical changes following oxidative stress as protective responses to cellular damage and not necessary harmful events. These considerations may explain the failure of supplementation of omega-3 FA in clinical practice (McCarthy 2014).

Oxidative stress is related also to $\mathrm{C} 1$ cycle, where amino acid homocysteine (HCy) is a key metabolite. Hyperhomocysteinemia over $10 \mu \mathrm{mol} / 1$ is considered a significant risk factor for CVD as well as for affective disorders. HCy level was not changed after medication of antidepressant fluoxetine. However, lowering $\mathrm{HCy}$ level in patients supplemented with folic acid resulted in antidepressive actions more efficient than those seen in patients treated with fluoxetine alone (Coppen and Bailey 2000, Severus et al. 2001).

At the physiological conditions, $\mathrm{HCy}$ reacts with endothelial NO, endothelium-derived relaxing factor (EDRF) to form S-nitrosohomocysteine with vasodilatory and antiplatelet effects. $\mathrm{HCy}$ is metabolized by two different pathways. One is re-methylation of $\mathrm{HCy}$ to methionine with N5-methyltetrahydrofolate and vitamin B12 as cofactors. Subsequent activation of methionine by adenosine triphosphate to form $\mathrm{S}$-adenosylmethionine is required. The second pathway is transsulfuration reaction in which cysteine is formed with vitamin B6 as a cofactor (Fig. 5). From methionine is formed S-adenosylmethionine, a basic methylation agent in the metabolism for methylation of proteins. During proteolysis from methylated rest of arginine unit asymmetric dimethylarginine (ADMA) can be formed. ADMA can competitively inhibit endothelial eNOS and thus inhibit NO production leading to endothelium dysfunction (Dayal and Lentz 2005). Similarly, neuronal nNOS can be inhibited by ADMA in cerebrospinal fluids (Pluta 2008). In addition to simple proteins, also histones in deoxyribonucleoproteins (during histones methylation) and fatty acids in lipids (during elongation of PUFA) can be methylated by ADMA. By this way, epigenetic regulation of omega-3 FA synthesis can be performed (Fig. 5). On the other hand, during transsulfuration pathway, HCy can be converted to cysteine, a basic precursor for synthesis of important endogenous antioxidant glutathione.

However, at high level $\mathrm{HCy}$ can be converted into HCy-thiolactone (Jakubowski 2008). Through autooxidation of $\mathrm{HCy} \mathrm{H}_{2} \mathrm{O}_{2}$ and superoxide can be formed and contribute to endothelial toxicity (Stamler $e t$ al. 1993). Moreover, HCy can inhibit glutathione peroxidase, an antioxidant enzyme degrading hydrogen peroxide. All these processes may result in increased oxidative stress. At increased level, superoxide can react with NO to form highly toxic peroxynitrite ONOO-. This reaction decreases the availability of $\mathrm{NO}$ for guanylate cyclase resulting in reduced vasodilatation. 


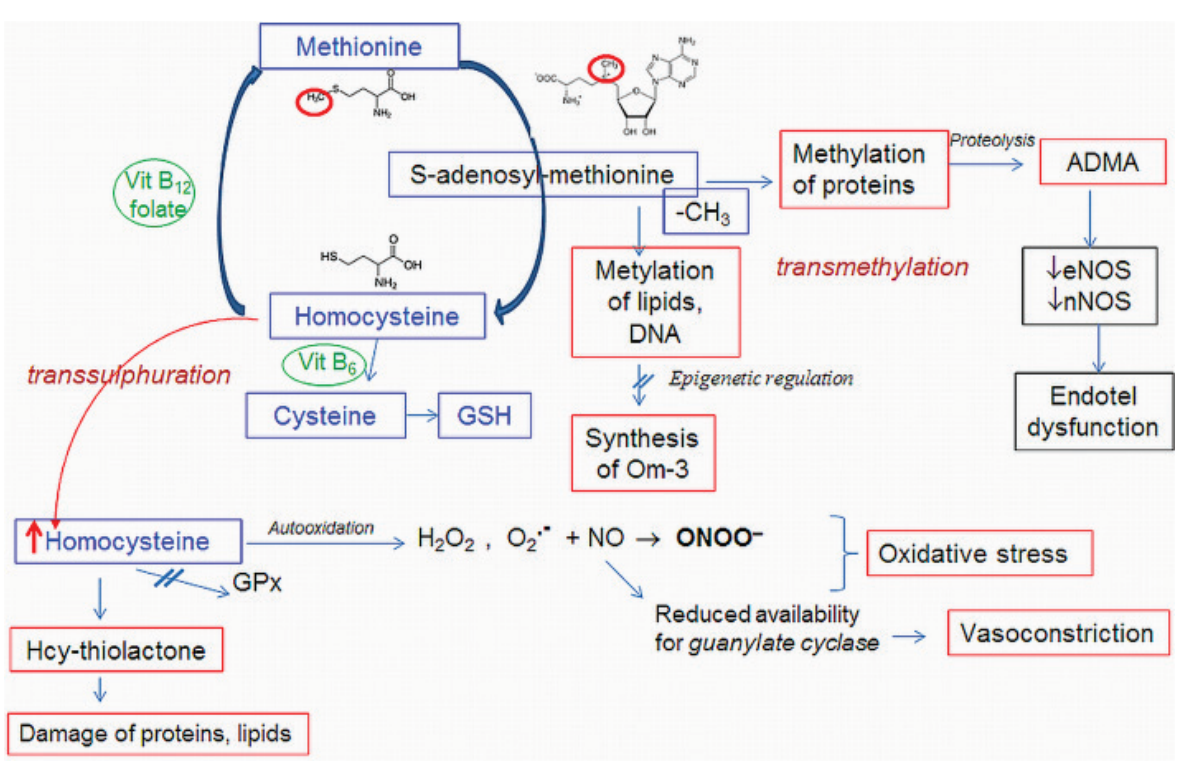

Fig. 5. Involvement of hyperhomocysteinemia in oxidative stress and metabolism of fatty acids. AA - arachidonic acid, BBB - blood brain barrier, DHA - docosahexanoic acid, LA - linoleic acid, ALA - alpha linolenic acid, FABP - fatty acid binding protein, GFL - glycerolphospholipid, TAG - triacylglycerol, VLDL - very low density lipoprotein.
Elevated homocysteine level was found in CVD risk patients as well as in depressed patients (Severus et al. 2001). However, several clinical trials using vitamin $B$ supplements to correct hyperhomocysteinemia failed to reduce the risk for CVD (Baggott and Tamura 2015). Authors supposed a possible relation of HCy to oxidative stress through association with ,free iron“ (non-protein bound iron) which is involved in formation of homocysteine from methionine, S-adenosylhomocysteine and cystathionine leading to increased circulating homocysteine. „Free iron“" is involved in formation of reactive oxygen species (Ďuračková 2014) and oxidized low-density lipoproteins known as risk factors for damage to macromolecules in both, cardiovascular and psychiatric disorders, mostly in chronic conditions (Assies et al. 2014).

Another new risk factor for CVD and depression is being discussed at present. Skaaby (2015) concluded that vitamin D, in addition to being an essential factor for bone mineralization, at low level is associated with mortality and several diseases ranging from CVD to autoimmune and liver diseases. Sufficient level of vitamin D was defined as $>50 \mathrm{nmol} / \mathrm{l}$. Enhanced vitamin D level are associated with a decrease in triacylglycerols and very low density lipoprotein cholesterol.

Sub-optimal level of vitamin D was also determined in people with schizophrenia and other psychotic disorders (Berk et al. 2008, Menkes et al. 2012, Durmaz et al. 2016). As previously said, people with psychosis demonstrate high level of cardiovascular risk.
However, detailed data are missing. In patients with psychotic disorders Lally et al. (2016) have found the negative association between vitamin D level and CVD risk factors such as waist circumference, triacylglycerols, total cholesterol, fasting glucose, Hemoglobin subunit alpha 1 and serum CRP levels. Significant association between depressive symptoms and physical condition in patients with chronic heart failure has been observed only in patients with vitamin D levels $<50 \mathrm{nmol} / 1$ (Johansson et al. 2016). The reason for these associations is not quite understood. There is accumulating evidence that vitamin D deficiency may be associated with inflammatory processes. Negative correlations were observed in patients with diabetes mellitus between level of vitamin D and circulating concentration of proinflammatory IL-1 beta and IL-6, but not between TNF alpha and interferon gamma (Tiwari et al. 2014). In patients with schizophrenia a negative correlation between vitamin D level and C-reactive protein was observed, especially in patients with elevated CRP (Zhu et al. 2015).

Depressed individuals in contrary to non-depressed subjects have one or more of these risk factors, and therefore the link between depression and CVD may be, in part, due to risk factor clustering (Joynt et al. 2003) (Fig. 6). All this knowledge confirms the existence of a common underlying factor for both pathologies. This factor represents response based on dramatic dietary changes that occurred after the agricultural and technological revolution in the mid-19th century (Simopoulos 2002) (Fig. 6). 


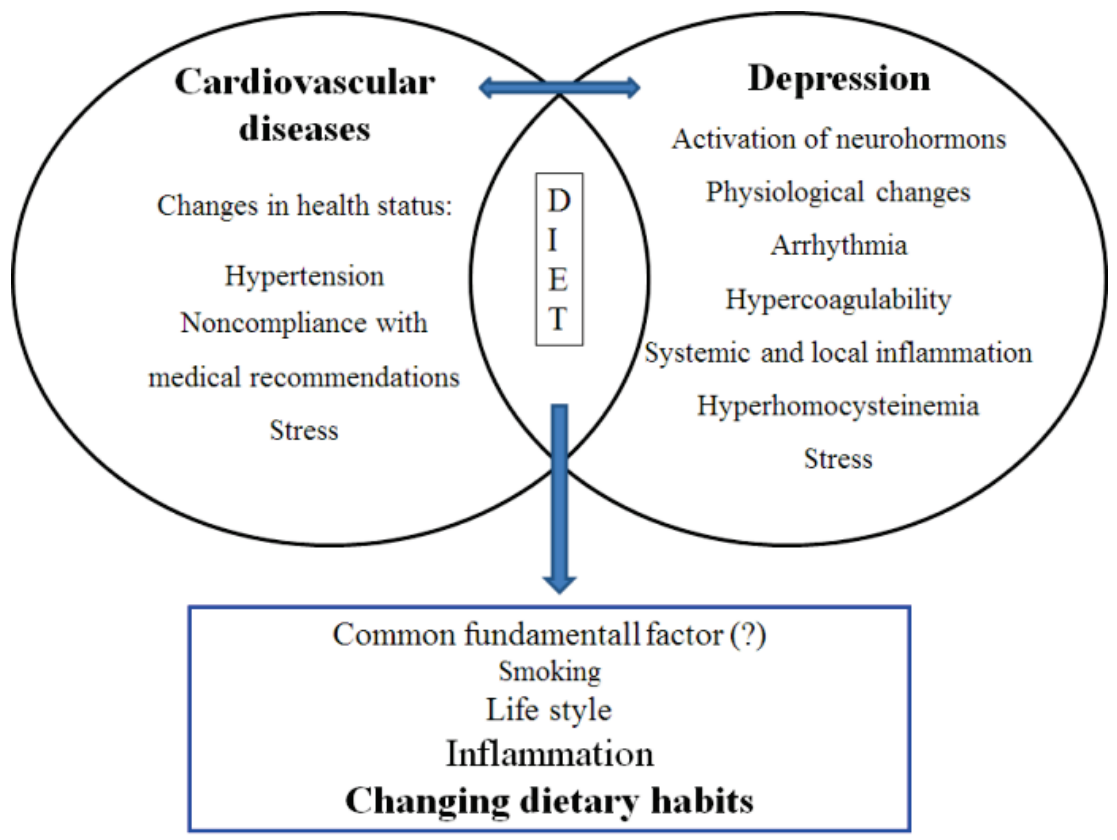

Fig. 6. Potential mechanisms of the relationship between cardiovascular diseases and depression. Their relationship is based on changes in health status (physiological state) and in psychological states underlined by factors causing both cardiovascular diseases and depression.

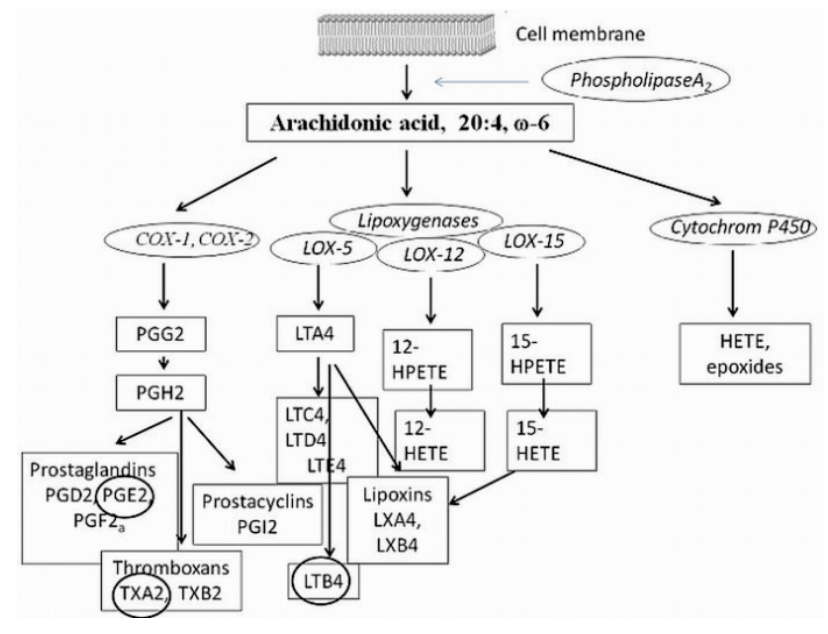

Fig. 7. Synthesis of AA metabolites. COX - cyclooxygenase, LOX - lipoxygenase, PG - prostaglandin, TX - thromboxan, PGI - prostacyclin, LX - lipoxin, LT - leukotriene, HPETE - hydroperoxyeicosatetraenoic acid, HETE - hydroxyeicosatetraenoic acid. Circled prostaglandin PGE2, thromboxane TXA2 and leukotriene LTB4 have the largest pro-inflammatory effects.

\section{Why are omega-3 FAs important for physical and mental health?}

The physiological/pathophysiological effects of unsaturated fatty acids in the body are not the same. The main cause of the harmful effects of arachidonic acid in comparison with omega-3 FA is the formation of pro-inflammatory eicosanoids (Fig. 7), whereas antiinflammatory eicosanoids are produced from the EPA. Structures of pro-inflammatory and anti-inflammatory eicosanoids consisting of AA, EPA and the precursor of AA synthesis, dihomo-gamma- linolenic acid (DGLA) are depicted in Figure 8. The proinflammatory eicosanoids have an even number of double bonds, while anti-inflammatory eicosanoids have an odd number of double bonds.

Moreover, in addition to anti-inflammatory prostaglandins PGF1 (Fig. 8), also other anti-inflammatory eicosanoids are synthesized from DGLA, such as e.g. thromboxane TXA1. From the omega-3 fatty acid, EPA, in addition to anti-inflammatory PGF3 there are synthesized also the anti-inflammatory eicosanoids such as thromboxane TXA3 and leukotriene LT5. Moreover, from the EPA and DHA by the catalytic action of lipoxygenases so-called resolvins and protectins are synthesized blocking the production of pro-inflammatory prostanoids. Resolvins were first described by Serhan (2005) as oxygenation products of acids EPA (E series) and DHA (D series) that are present at sites of inflammation at nanomolar and picomolar concentrations. These substances have been isolated from the exudate of inflammatory site (resolving inflammatory exudate). In recent years resolvins have been studied particularly with regard to CVD. They are especially ethanolamide of docosahexaenoic acid (DHEA) and other derivatives inhibiting COX2 similarly to acetic acid released from aspirin during COX1 inhibition (aspirintriggered form of protectins, ATPD1). These compounds block the PMNL chemotaxis; they reduce expression of P-selectin, adhesion of leukocytes to the thromboxanes, in order to protect organs during ischemia-reperfusion injury (Alessandri et al. 2004). ATPD1 reduces transendothelial migration of PMNL and increases 
macrophage eferocytosis of apoptotic PMNL (Shinohara et al. 2012). Further experiments could clarify whether these anti-inflammatory and immunoregulatory reactions find application in the inflammatory responses of the nervous tissue in the brain.

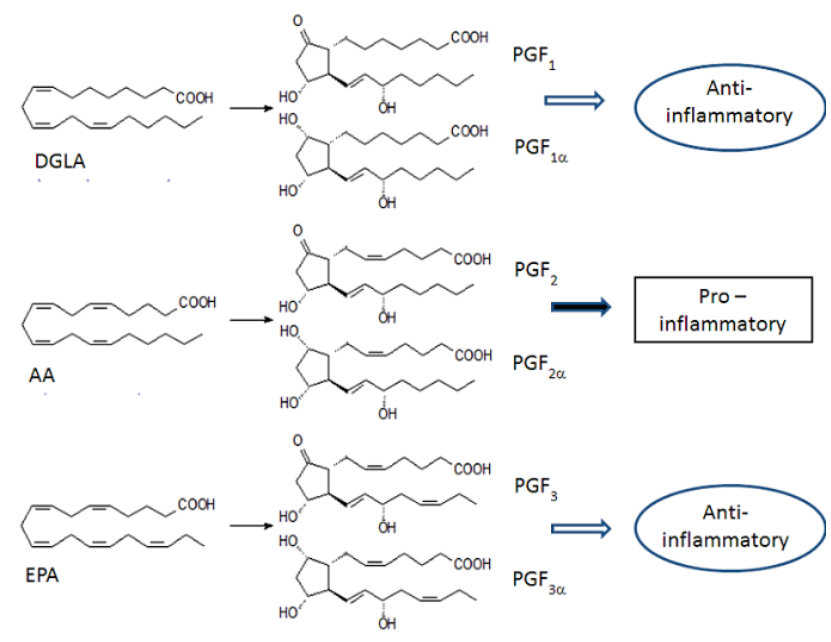

Fig. 8. Metabolites of $A A, E P A$ and $D H A$. PGF - prostaglandin $F$, $A A$ - arachidonic acid, EPA - eicosapentaenoic acid, DGLA - dihomo-gama-linolenic acid.

Omega-3 fatty acids may contribute to the protective effects on cells of the CNS not only by biochemical processes but also by mechanical/ biophysical mechanisms. Fatty acids are part of phospholipids and in this form they are part of cell membranes. The composition of lipids in the membranes affects the important property of membranes - the fluidity (flowability) of nerve cell membranes. Under the fluidity of the membrane we mean the free movement of FA hydrophobic chains in the bilayer of a biological membrane. Residues of FA chains within the membrane may perform different movements depending on the structure (chain length, number of double bonds) - flexion, rotation, lateral diffusion, bobbing and flip-flop (Fig. 9). Generally, improved fluidity of the membrane is associated with a reduction of the ratio of saturated phospholipid to unsaturated, sphingomyelin to phosphatidylcholine, cholesterol to phospholipids (Yao and van Kammen 1994). Longer polyunsaturated FA fluidize membranes more than shorter FA (they need more space for the oscillating motion of the hydrophobic chain in the membrane). Moreover, a longer FA embedded in the membrane (e.g. DHA) contributes to the increased size of lipoprotein particles LDL and HDL characterized by an atheroprotective effect (Oravec et al. 2011, Muchová et al. 2016).

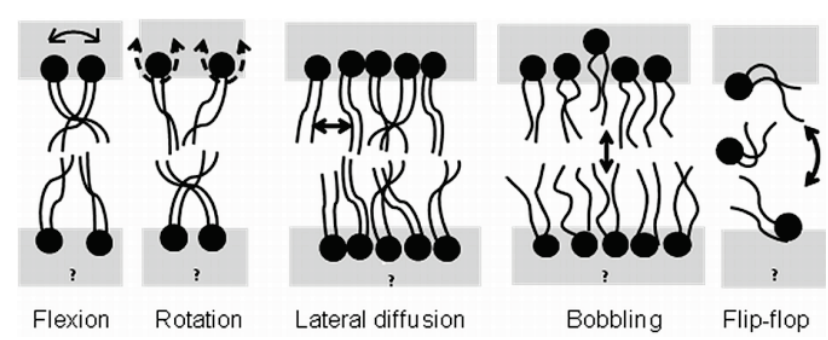

Fig. 9. Movement of hydrophobic chains of fatty acids in a biological membrane.

In addition to the composition of FA, membrane fluidity is influenced also by other factors, e.g. oxidative damage, presence of cholesterol, presence of membrane proteins or saccharides and temperature. A change in the membrane fluidity results in a change in membrane properties, such as density and binding affinity of neurotransmitters and neurohormones, including serotonin, norepinephrine and dopamine. Conversely, fluidity affects the function of proteins embedded in the membrane (receptors, transporters), and thus the function of the membrane.

Key protective effect of DHA might be related to its spatial characteristics. The increased number of carbons and six double bonds in the DHA molecule (22:6), as reported above, needs more space for its existence in a membrane than EPA, thereby increasing the fluidity of the membrane, which is critical especially for the synapse, and is needed for the rotation of receptors and signal transmission from the membrane surface inside a nerve cell (Stillwell and Wassall 2003).

EPA is present in the brain only in small quantities, so initially it was assumed to have no significance for proper brain function. However, EPA may improve some mental disorders and has a role in brain function. The most important function of the EPA in the brain is the inhibition of the inflammatory response and the stimulation of cell signaling mediated by anti-inflammatory eicosanoids. In addition, EPA competitively inhibits different desaturase, than DHA, delta-5 desaturase (D5D), necessary for the synthesis of AA. EPA is also a competitor for the incorporation of AA into membranes of nerve cells, but also for phospholipase 2, catalyzing the release of AA from membranes. By the inhibition of AA production and its release from membranes the formation of inflammatory eicosanoids is inhibited (Fig. 10).

Less information is available about the relationship between the pathophysiology of the depressive disorder, and cardiovascular diseases in 
children (Tonhajzerová and Ondrejka 2008). Epidemiological studies indicate a protective role of omega-3 FA against CVD in adults. In children, their potential beneficial effect for insulin sensitivity in boys but not in girls (Burrows et al. 2011) and blood pressure control (O'Sullivan et al. 2012) were observed. Mechanisms through which omega-3 FA act are not quite known. But it is supposed that interaction with ion channel and influence on plasma membrane fluidity are involved. Omega-3 FA can act also as competitors for cytochrome P-450 with respect to omega-6 FA and thus can modulate the biosynthesis of eicosanoids with protective action. The complex interactions of different nutrients including polyunsaturated FA and polymorphism in genes involved in omega-3 FA metabolism should be kept in mind (Bonafini et al. 2015).

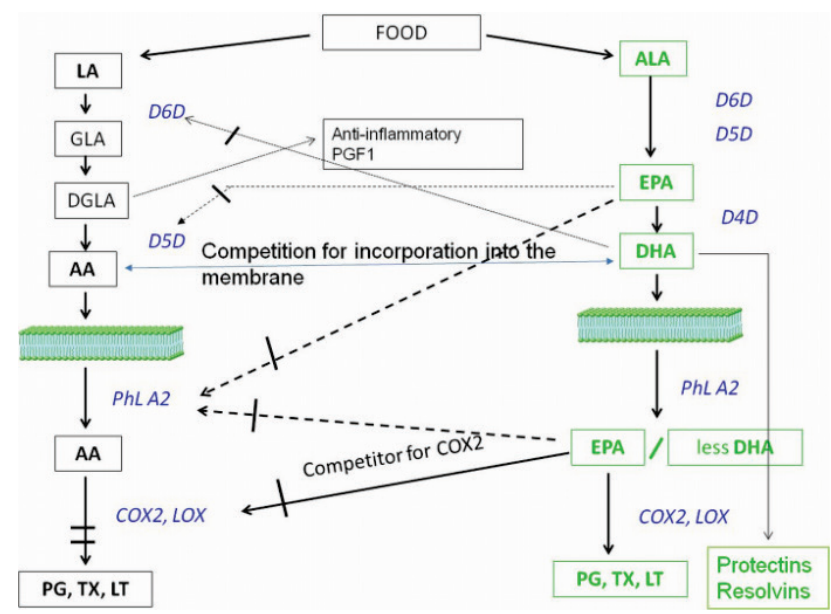

Fig. 10. Mutual relation of LA and ALA metabolites. ALA - alpha linolenic acid, COX - cyclooxygenase, D4D - delta-4-desaturase, D5D - delta-5-desaturase, D6D - delta-6-desaturase, DGLA - dihomo-gama-linolenic acid, DHA - docosahexanoic acid, EPA - eicosapentaenoic acid, GLA - gama linolenic acid, LA - linoleic acid, LT - leukotriene, LOX - lipoxygenase, PG - prostaglandin, PhL - phospholipase, $\mathrm{TX}$ - thromboxane.

Studies examining the antidepressant effects of individual nutritional supplements in children and adolescents are also assessed (Lopresti 2015). The antidepressant effects of omega-3 FA are believed to be derived from one or several of its biological effects: (1) antiinflammatory effect through decreasing of pro-inflammatory mediators (Grosso et al. 2014), (2) modulation of synaptic plasticity and enhanced neurotransmission (Crupi et al. 2013), (3) increasing of membrane fluidity (Avorech et al. 2015), (4) influencing of hypothalamus-pituitary adrenal axis activity through cortisol regulation (Barbadoro et al. 2013). All these potential pathophysiological mechanisms can be also applied in CVD.

The preliminary positive support for the antidepressant effects of omega-3 FA for youth depression is provided from only two studies (Nemets et al. 2006, McNamara et al. 2014). Results from our study with 35 depressive children and adolescents supplemented with fish oil emulsion rich in omega-3 FA indicate the reduction of depressive symptoms evaluated as CDI score after 3 months intervention (Trebaticka et al. 2017).

Correlation between the impact of omega-3 FA on the pathophysiology of CVD and depression was also manifested in the study of the impact of omega-3 FA on lipid profile. Our results from the study of the effect of emulsified mixture of plant sterol esters $(1.3 \mathrm{~g})$, fish oil (1 g EPA+DHA), vitamin B12 (50 $\mu \mathrm{g})$, B6 (2.5 mg), folic acid $(0.8 \mathrm{mg})$ and coenzyme Q10 (3 $\mathrm{mg})$ on lipid profile of hypercholesterolemic children indicate the increased anti-atherogenic IDL3 and LDL1 and reduced atherogenic ILD2 subfractions (Garaiova et al. 2013). In another study of ours with 35 depressive children and adolescents an increased anti-atherogenic large HDL subfractions and decreased atherogenic small HDL subfractions were observed after 3 months supplementation with emulsion of fish oil rich in omega-3 FA (unpublished results).

Although results of the impact of omega-3 FA from meta-analyses are sometimes contradictory, positive effect on physical and mental health is unambiguous. However, various professional societies differ in the recommendation of appropriate doses and duration of omega-3 FA supplementation for both CVD and mental health (Graham et al. 2007, Vrablík et al. 2009).

For the Europeans daily recommended dose of DHA and EPA is $300-600 \mathrm{mg}$ for the primary prevention and $900-1,200 \mathrm{mg}$ for the secondary prevention, minimum daily dose for adults is $250 \mathrm{mg}$ EPA+DHA, for pregnant women is $200-300 \mathrm{mg}$, for children aged 7 - 24 months $-100 \mathrm{mg}$ DHA, children aged $2-18$ years - $250 \mathrm{mg}$ EPA+DHA (Simopoulos 2002, Grosso et al. 2014, Gow and Hibbeln 2014). The recommended intake of omega-3 FAs can be reached by the consumption of fish (preferably fatty fish such as salmon, mackerel, tuna, sardines) twice a day. However, to reduce TAG the intake of omega-3 FA must be increased to 3-4 g of per day.

The question is the appropriate ratio of EPA and DHA in the supplements used and supplement 
forms - capsules or oils or oil emulsions. In the case of CVD recommended ratio EPA:DHA is $1: 2$; for mental disorders recommended composition of supplement is at least $60 \% \mathrm{EPA}$ and $40 \% \mathrm{DHA}$. It is recommended to follow instructions in the leaflet inserted in supplement packages and check supplement composition (ratio of EPA and DHA). Capsules and emulsions have not the same ability to be absorbed through the digestive tract. Omega-3 FAs from the emulsions are better absorbed compared to the uptake of triacylglycerols from fish oil contained in capsules. Moreover, the emulsion can be adjusted to the desired flavor and taste and in the emulsified form the access of lipases (enzymes necessary for the release of fatty acids from lipids) to the lipids is improved (Garaiova et al. 2007, Raatz 2009).

\section{Conclusions}

Depression and CVD are linked through some pathophysiological events. Their relation is bi-directional. Depression not only increases, but also predicts the risk of adverse cardiovascular events in patients with established heart disease, but it also predicts incidence of CVD in individuals with no history of cardiac problems. On the other hand, CVD influence affective states and may induce depression. Specific neurophysiological and behavioral abnormalities have been observed in depressed patients, which may account for the relationship to CVD. This mutual relation may be mediated via the pathophysiological pathways that are shared between CVD and depression, like neurohormonal activation, rhythm disturbance, inflammation and hypercoagulability. Each of these areas of interconnection represents a potential therapeutic intervention to improve both, CVD and depression.

However, better understanding of the links between depression and CVD will require large and well-designed clinical trials with assembling of both, physiological and behavioral outcomes. Obtained results could explain open questions and improve quality of life, reduce time of hospitalization, decrease mortality and last but not least can reduce the economic burdens incurred in relation to CVD and psychiatric disorders.

\section{Conflict of Interest}

There is no conflict of interest.

\section{Acknowledgements}

This work was supported by grant of Ministry of Education of SR 01/0703/2013, APVV grant 15-0063 and Mind and Health, civil association. Authors wish to thank to Dr. I. Žitňanová for help with English and Ms. L. Míková for technical assistance with literature.

\section{References}

AKBAR M, CALDERON F, WEN Z, KIM HY: Docosahexaenoic acid: a positive modulator of Akt signaling in neuronal survival. Proc Natl Acad Sci U S A 102: 10858-10863, 2005.

ALESSANDRI JM, GUESNET P, VANCASSEL S, ASTORG P, DENIS I, LANGELIER B, AÏD S, POUMĖS-BALLIHAUT C, CHAMPEIL-POTOKAR G, LAVIALLE M: Polyunsaturated fatty acids in the central nervous system: evolution of concepts and nutritional implications throughout life. Reprod Nutr Dev 44: 509-538, 2004.

APPLETON KM, HAYWARD RC, GUNNELL D, PETERS TJ, ROGERS PJ, KESSLER D, NESS AR: Effects of n-3 long-chain polyunsaturated fatty acids on depressed mood: systematic review of published trials. Am J Clin Nutr 84: 1308-1316, 2006.

ASSIES J, MOCKING RJT, LOK A, RUHÉ HG, POUWER F, SCHENE AH: Effects of oxidative stress on fatty acid- and one-carbon-metabolism in psychiatric and cardiovascular disease comorbidity. Acta Psychiatr Scand 130: $163-180,2014$.

ASTORG P, COUTHOUIS A, BERTRAIS S, ARNAULT N, MENETON P, GUESNET P, ALESSANDRI JM, GALAN P, HERCBERG S: Association of fish and long-chain n-3 polyunsaturated fatty acid intakes with the occurrence of depressive episodes in middle-aged French men and women. Prostaglandins Leukot Essent Fatty Acids 78: 171-182, 2008.

AYORECH Z, TRACY DK, BAUMEISTER D, GIAROLI G: Taking the fuel out of the fire: evidence for the use of anti-inflammatory agents in the treatment of bipolar disorders. J Affect Disord 174: 467-478, 2015. 
BAGGOTT JE, TAMURA T: Homocysteine, iron and cardiovascular disease: a hypothesis. Nutrients 7: 1108-1118, 2015.

BARBADORO P, ANNINO I, PONZIO E, ROMANELLI RM, D'ERRICO MM, PROSPERO E, MINELLI A: Fish oil supplementation reduces cortisol basal levels and perceived stress: a randomized, placebo-controlled trial in abstinent alcoholics. Mol Nutr Food Res 57: 1110-1114, 2013.

BERK M, JACKA FN, WILLIAMS LJ, NG F, DODD S, PASCO JA: Is this D vitamin to worry about? Vitamin D insufficiency in an inpatient sample. Aust N Z J Psychiatry 42: 874-878, 2008.

BONAFINI S, ANTONIAZZI F, MAFFEIS C, MINUZ P, FAVA C: Beneficial effects of $\omega-3$ PUFA in children on cardiovascular risk factors during childhood and adolescence. Prostaglandins Other Lipid Mediat 120: 72-79, 2015.

BUOLI M, ALTAMURA AC: May non-antipsychotic drugs improve cognition of schizophrenia patients? Pharmacopsychiatry 48: 41-50, 2015.

BURR ML, ASHFIELD-WATT PA, DUNSTAN FD, FEHILY AM, BREAY P, ASHTON T, ZOTOS PC, HABOUBI NA, ELWOOD PC: Lack of benefit of dietary advice to men with angina: results of a controlled trial. Eur J Clin Nutr 57: 193-200, 2003.

BURR ML, DUNSTAN FD, GEORGE CH: Is fish oil good or bad for heart disease? Two trials with apparently conflicting. Results J Membr Biol 206: 155-163, 2005.

BURROWS T, COLLINS CE, GARG ML: Omega-3 index, obesity and insulin resistance in children. Int $J$ Pediatr Obes 6: e532-e539, 2011.

CABALLERO-MARTÍNEZ F, LEÓN-VÁZQUEZ F, PAYÁ-PARDO A, DÍAZ-HOLGADO A: Use of health care resources and loss of productivity in patients with depressive disorders seen in Primary Care: INTERDEP Study. Actas Esp Psiquiatr 42: 281-291, 2014.

CALDER PC, YAQOOB P: Omega-3 polyunsaturated fatty acids and human health outcomes. Biofactors 35: $266-272$, 2009.

CALDER PC: Long chain fatty acids and gene expression in inflammation and immunity. Curr Opin Clin Nutr Metab Care 16: 425-433, 2013.

CALDER PC: Polyunsaturated fatty acids and inflammatory processes: New twists in an old tale. Biochimie 91: 791-795, 2009.

CEDERHOLM T, SALEM N JR, PALMBLAD J: $\omega-3$ fatty acids in the prevention of cognitive decline in humans. $A d v$ Nutr 4: 672-676, 2013.

CHALON S, DELION-VANCASSEL S, BELZUNG C, GUILLOTEAU D, LEGUISQUET AM, BESNARD JC, DURAND G: Dietary fish oil affects monoaminergic neurotransmission and behavior in rats. $J$ Nutr 128: 2512-2519, 1998.

CHEN C, YU X, SHAO S: Effects of omega-3 fatty acid supplementation on glucose control and lipid levels in type 2 diabetes: a meta-analysis. PLoS One 10: e0139565, 2015.

CHEN Q, CHENG LQ, XIAO TH, ZHANG YX, ZHU M, ZHANG R, LI K, WANG Y, LI Y: Effects of omega-3 fatty acid for sudden cardiac death prevention in patients with cardiovascular disease: a contemporary meta-analysis of randomized, controlled trials. Cardiovasc Drugs 25: 259-265, 2011.

CONNOR SL, CONNOR WE: Are fish oils beneficial in the prevention and treatment of coronary artery disease? Am J Clin Nutr 66: 1020S-1031S, 1997.

COPPEN A, BAILEY J: Enhancement of the antidepressant action of fluoxetine by folic acid: a randomised, placebo controlled trial. J Affect Disord 60: 121-130, 2000.

CRUPI R, MARINO A, CUZZOCREA S: n-3 fatty acids: role in neurogenesis and neuroplasticity. Curr Med Chem 20: 2953-2963, 2013.

DAYAL S, LENTZ SR: ADMA and hyperhomocysteinemia. Vasc Med 10: S27-S33, 2005.

DE VRIESE SR, CHRISTOPHE AB, MAES M: In humans, the seasonal variation in poly-unsaturated fatty acids is related to the seasonal variation in violent suicide and serotonergic markers of violent suicide. Prostaglandins Leukot Essent Fatty Acids 71: 13-18, 2004.

DELGADO-LISTA J, PEREZ-MARTINEZ P, LOPEZ-MIRANDA J, PEREZ-JIMENEZ F: Long chain omega-3 fatty acids and cardiovascular disease: a systematic review. Br J Nutr 107: S201-S213, 2012. 
Di MINNO MND, TREMOLI E, TUFANO A, RUSSOLILlO A, LUPOLI R, Di MINNO G: Exploring newer cardioprotective strategies: $\omega-3$ fatty acids in perspective. Thromb Haemost 104: 664-680, 2010.

DIN JN, ARCHER RM, HARDING SA, SARMA J, LYALL K, FLAPAN AD, NEWBY DE: Effect of $\omega-3$ fatty acid supplementation on endothelial function, endogenous fibrinolysis and platelet activation in male cigarette smokers. Heart 99: 168-174, 2013.

DIN JN, NEWBY DE, FLAPAN AD: Omega 3 fatty acids and cardiovascular disease - fishing for a natural treatment. BMJ 328: 30-35, 2004.

DIN JN, SARMA J, HARDING SA, LYALL K, NEWBY DE, FLAPAN AD: Effect of $\omega$-3 fatty acid supplementation on endothelial function, endogenous fibrinolysis and platelet activation in patients with a previous myocardial infarction: a randomised controlled trial. BMJ Open 3: e003054, 2013.

DOWLATI Y, HERRMANN N, SWARDFAGER W, LIU H, SHAM L, REIM EK, LANCTÔT KL: A meta-analysis of cytokines in major depression. Biol Psychiatry 67: 446-457, 2010.

ĎURAČKOVÁ Z: Free radicals and antioxidants for non-experts. In: Systems Biology of Free Radicals and Antioxidants, Vol. 1. LAHER I (ed.), Springer, Berlin, 2014, pp 3-38.

ĎURAČKOVÁ Z: Some current insights into oxidative stress. Physiol Res 59: 459-469, 2010.

DURMAZ O, OLGUN KUCUK H, KUCUK U: Intricate associations between heart failure, depression and vitamin D. Int J Cardiol 212: 121, 2016.

EDWARDS R, PEET M, SHAY J, HORROBIN D: Omega-3 polyunsaturated fatty acid levels in the diet and in red blood cell membranes of depressed patients. J Affect Disord 48: 149-155, 1998.

FAROOQUI AA, HORROCKS LA, FAROOQUI T: Modulation of inflammation in brain: a matter of fat. $J$ Neurochem 101: 577-599, 2007.

FAROOQUI AA: Lipid mediators in the neural cell nucleus: their metabolism, signaling, and association with neurological disorders. Neuroscientists 15, 392-407, 2009.

FREEMAN MP, HIBBELN JR, WISNER KL, DAVIS JM, MISCHOULON D, PEET M, KECK PE JR, MARANGELL LB, RICHARDSON AJ, LAKE J, STOLL AL: Omega-3 fatty acids: evidence basis for treatment and future research in psychiatry. J Clin Psychiatry 67: 1954-1967, 2006.

GARAIOVA I, GUSCHINA IA, PLUMMER SF, TANG J, WANG D, PLUMMER NT: A randomised cross-over trial in healthy adults indicating improved absorption of omega-3 fatty acids by pre-emulsification. Nutr $J$ 6: 4, 2007.

GARAIOVA I, MUCHOVÁ J, NAGYOVÁ Z, MIŠLANOVÁ C, ORAVEC S, DUKÁT A, WANG D, PLUMMER SF, ĎURAČKOVÁ Z: Effect of a plant sterol, fish oil and B vitamin combination on cardiovascular risk factors in hypercholesterolemic children and adolescents: a pilot study. Nutr J 12: 7, 2013.

GOW RV, HIBBELN JR, PARLETTA N: Current evidence and future directions for research with omega-3 fatty acids and attention deficit hyperactivity disorder. Curr Opin Clin Nutr Metab Care 18: 33-138, 2015.

GOW RV, HIBBELN JR: Omega-3 fatty acid and nutrient deficits in adverse neurodevelopment and childhood behaviors. Child Adolesc Psychiatr Clin N Am 23: 555-590, 2014.

GRAHAM I, ATAR D, BORCH-JOHNSEN K, BOYSEN G, BURELL G, CIFKOVA R, DALLONGEVILLE J, DE BACKER G, EBRAHIM S, GJELSVIK B, ET AL.: European guidelines on cardiovascular disease prevention in clinical practice: executive summary: Fourth joint task force of the European society of cardiology and other societies on cardiovascular disease prevention in clinical practice (constituted by representatives of nine societies and by invited experts). Eur Heart J 28: 2375-2414, 2007.

GRIPPO AJ, JOHNSON AK: Biological mechanisms in the relationship between depression and heart disease. Neurosci Biobehav Rev 26: 941-962, 2002.

GROSSO G, GALVANO F, MARVENTANO S, MALAGUARNERA M, BUCOLO C, DRAGO F, CARACI F: Omega-3 fatty acids and depression: scientific evidence and biological mechanisms. Oxid Med Cell Longev 2014: $313570,2014$.

HAKKARAINEN R, PARTONEN T, HAUKKA J, VIRTAMO J, ALBANES D, LÖNNQVIST J: Is low dietary intake of omega-3 fatty acids associated with depression? Am J Psychiatry 161: 567-569, 2004.

HARE DL, TOUKHSATI SR, JOHANSSON P, JAARSMA T: Depression and cardiovascular disease: a clinical review. Eur Heart J 35: 1365-1372, 2014. 
HARRIS WS, MILLER M, TIGHE AP, DAVIDSON MH, SCHAEFER EJ: Omega-3 fatty acids and coronary heart disease risk: clinical and mechanistic perspectives. Atherosclerosis 197: 12-24, 2008.

HARRIS WS: The omega-3 index as a risk factor for coronary heart disease. Am J Clin Nutr 87: 1997S-2002S, 2008.

HIBBELN JR: Fish consumption and major depression. Lancet 351: 1213, 1998.

ITO H, KAWASHIMA R, AWATA S, ONO S, SATO K, GOTO R, KOYAMA M, SATO M, FUKUDA H: Hypoperfusion in the limbic system and prefrontal cortex in depression: SPECT with anatomic standardization technique. J Nucl Med 37: 410-414, 1996.

JACKA FN, PASCO JA, HENRY MJ, KOTOWICZ MA, NICHOLSON GC, BERK M: Dietary omega-3 fatty acids and depression in a community sample. Nutr Neurosci 7: 101-106, 2004.

JAIN AP, AGGARWAL KK, ZHANG PY: Omega-3 fatty acids and cardiovascular disease. Eur Rev Med Pharmacol Sci 19: 441-445, 2015.

JAKUBOWSKI H: The pathophysiological hypothesis of homocysteine thiolactone-mediated vascular disease. J Physiol Pharmacol 59: 155-167, 2008.

JOHANSSON P, ALEHAGEN U, VAN DER WAL MH, SVENSSON E, JAARSMA T: Vitamin D levels and depressive symptoms in patients with chronic heart failure. Int $J$ Cardiol 207: 185-189, 2016.

JOYNT KE, WHELLAN DJ, O'CONNOR CM: Depression and cardiovascular disease: mechanisms of interaction. Biol Psychiatry 54: 248-261, 2003.

JOYNT KE, WHELLAN DJ, O'CONNOR CM: Why is depression bad for the failing heart? A review of the mechanistic relationship between depression and heart failure. J Card Fail 10: 258-271, 2004.

KEARNS SD, HAAG M: The effect of omega-3 fatty acids on Ca-ATPase in rat cerebral cortex. Prostaglandins Leukot Essent Fatty Acids 67: 303-308, 2002.

KUPERSTEIN F, EILAM R, YAVIN E: Altered expression of key dopaminergic regulatory proteins in the postnatal brain following perinatal n-3 fatty acid dietary deficiency. J Neurochem 106: 662-671, 2008.

KYROZIS A, PSALTOPOULOU T, STATHOPOULOS P, TRICHOPOULOS D, VASSILOPOULOS D, TRICHOPOULOU A: Dietary lipids and geriatric depression scale score among elders: the EPIC-Greece cohort. J Psychiatr Res 43: 763-769, 2009.

LALLY J, GARDNER-SOOD P, FIRDOSI M, IYEGBE C, STUBBS B, GREENWOOD K, MURRAY R, SMITH S, HOWES O, GAUGHRAN F: Clinical correlates of vitamin D deficiency in established psychosis. BMC Psychiatry 16: 76, 2016.

LATOUR A, GRINTAL B, CHAMPEIL-POTOKAR G, HENNEBELLE M, LAVIALLE M, DUTAR P, POTIER B, BILLARD JM, VANCASSEL S, DENIS I: Omega-3 fatty acids deficiency aggravates glutamatergic synapse and astroglial aging in the rat hippocampal CA1. Aging Cell 12: 76-84, 2013.

LESLIE MA, COHEN DJ, LIDDLE DM, ROBINSON LE, MA DW: A review of the effect of omega-3 polyunsaturated fatty acids on blood triacylglycerol levels in normolipidemic and borderline hyperlipidemic individuals. Lipids Health Dis 14: 53, 2015.

LEVANT B, OZIAS MK, DAVIS PF, WINTER M, RUSSELL KL, CARLSON SE, REED GA, MCCARSON KE: Decreased brain docosahexaenoic acid content produces neurobiological effects associated with depression: Interactions with reproductive status in female rats. Psychoneuroendocrinology 33: 1279-1292, 2008.

LIBBY P: Inflammation in atherosclerosis. Nature 420: 868-874, 2002.

LIN PY, MISCHOULON D, FREEMAN MP, MATSUOKA Y, HIBBELN J, BELMAKER RH, SU KP: Are omega-3 fatty acids antidepressants or just mood-improving agents? The effect depends upon diagnosis, supplement preparation, and severity of depression. Mol Psychiatry 17: 1161-1163, 2012.

LIN PY, SU KP: A meta-analytic review of double-blind, placebo-controlled trials of antidepressant efficacy of omega-3 fatty acids. J Clin Psychiatry 68: 1056-1061, 2007.

LIU JJ, GREEN P, JOHN MANN J, RAPOPORT SI, SUBLETTE ME: Pathways of polyunsaturated fatty acid utilization: implications for brain function in neuropsychiatric health and disease. Brain Res 1597: 220-246, 2015.

LOPRESTI AL: A review of nutrient treatments for paediatric depression. J Affect Disord 181: 24-32, 2015. 
LU DY, TSAO YY, LEUNG YM, SU KP: Docosahexaenoic acid suppresses neuroinflammatory responses and induces heme oxygenase-1 expression in BV-2 microglia: implications of antidepressant effects for $\omega$-3 fatty acids. Neuropsychopharmacology 35: 2238-2248, 2010.

MA DW, SEO J, SWITZER KC, FAN YY, MCMURRAY DN, LUPTON JR, CHAPKIN RS: n-3 PUFA and membrane microdomains: a new frontier in bioactive lipid research. J Nutr Biochem 15: 700-706, 2004.

MAMALAKIS G, KIRIAKAKIS M, TSIBINOS G, KAFATOS A: Depression and adipose polyunsaturated fatty acids in an adolescent group. Prostaglandins Leukot Essent Fatty Acids 71: 289-294, 2004.

MARCHESELLI VL, HONG S, LUKIW WJ, TIAN XH, GRONERT K, MUSTO A, HARDY M, GIMENEZ JM, CHIANG N, SERHAN CN, BAZAN NG: Novel docosanoids inhibit brain ischemia-reperfusion-mediated leukocyte infiltration and pro-inflammatory gene expression. J Biol Chem 278: 43807-43817, 2003.

MCCARTHY MJ: Oxidative stress: a link between cardiovascular disease and psychiatric illness? Acta Psychiatr Scand 130: 161-162, 2014.

MCNAMARA RK, STRIMPFEL J, JANDACEK R, RIDER T, TSO P, WELGE JA, STRAWN JR, DELBELLO MP: Detection and treatment of long-chain omega-3 fatty acid deficiency in adolescents with SSRI-resistant major depressive disorder. PharmaNutrition 2: 38-46, 2014.

MENKES DB, LANCASTER K, GRANT M, MARSH RW, DEAN P, DU TOIT SA: Vitamin D status of psychiatric inpatients in New Zealand's Waikato region. BMC Psychiatry 12: 68, 2012.

MIZUSHIMA S, MORIGUCHI EH, ISHIKAWA P, HEKMAN P, NARA Y, MIMURA G, MORIGUCHI Y, YAMORI Y: Fish intake and cardiovascular risk among middle-aged Japanese in Japan and Brazil. J Cardiovasc Risk 4: 191-199, 1997.

MOSCA L: C-reactive protein - to screen or not to screen? N Engl J Med 347: 1615-1617, 2002.

MOSOVICH SA, BOONE RT, REICHENBERG A, BANSILAL S, SHAFFER J, DAHLMAN K, HARVEY PD, FARKOUH ME: New insights into the link between cardiovascular disease and depression. Int J Clin Pract 62: 423-432, 2008.

MOZAFFARIAN D, MARCHIOLI R, MACCHIA A, SILLETTA MG, FERRAZZI P, GARDNER TJ, LATINI R, LIBBY P, LOMBARDI F, O'GARA PT, ET AL:: Fish oil and postoperative atrial fibrillation: the Omega-3 Fatty Acids for Prevention of Post-operative Atrial Fibrillation (OPERA) randomized trial. JAMA 308: 2001-2011, 2012.

MUCHOVÁ J, ANDREZÁlOVÁ L, ORAVEC S, NAGYOVÁ Z, GARAIOVA I, ĎURAČKOVÁ Z: High density lipoprotein subfractions and paraoxonase 1 in children. Acta Biochim Pol 63: 555-563, 2016.

NEMETS H, NEMETS B, APTER A, BRACHA Z, BELMAKER RH: Omega-3 treatment of childhood depression: a controlled, double-blind pilot study. Am J Psychiatry 163: 1098-1100, 2006.

NESTEL P, CLIFTON P, COLQUHOUN D, NOAKES M, MORI TA, SULLIVAN D, THOMAS B: Indications for omega-3 long chain polyunsaturated fatty acid in the prevention and treatment of cardiovascular disease. Heart Lung Circ 24: 769-779, 2015.

NICHOLS M, TOWNSEND N, SCARBOROUGH P, RAYNER M: Cardiovascular disease in Europe 2014: epidemiological update. Eur Heart J 35: 2929, 2014.

OIKAWA S, YOKOYAMA M, ORIGASA H, MATSUZAKI M, MATSUZAWA Y, SAITO Y, ISHIKAWA Y, SASAKI J, HISHIDA H, ITAKURA H, ET AL.: Suppressive effect of EPA on the incidence of coronary events in hypercholesterolemia with impaired glucose metabolism: Sub-analysis of the Japan EPA Lipid Intervention Study (JELIS). Atherosclerosis 206: 535-539, 2009.

ORAVEC S, DUKÁT A, GAVORNÍK P, LOVÁSOVÁ Z, GRUBER K: Atherogenic normolipidemia - a new phenomenon in the lipoprotein profile of clinically healthy subjects. Neuro Endocrinol Lett 32: 317-321, 2011.

ORR SK, PALUMBO S, BOSETTI F, MOUNT HT, KANG JX, GREENWOOD CE, MA DW, SERHAN CN, BAZINET RP: Unesterified docosahexaenoic acid is protective in neuroinflammation. J Neurochem 127 : 378-393, 2013.

O'SULLIVAN TA, BREMNER AP, BEILIN LJ, AMBROSINI GL, MORI TA, HUANG RC, ODDY WH: Polyunsaturated fatty acid intake and blood pressure in adolescents. J Hum Hypertens 26: 178-187, 2012.

PATRICK RP, AMES BN: Vitamin D and the omega-3 fatty acids control serotonin synthesis and action, part 2: relevance for ADHD, bipolar disorder, schizophrenia, and impulsive behavior. FASEB J 29: 2207-2222, 2015. 
PIFFERI F, JOUIN M, ALESSANDRI JM, HAEDKE U, ROUX F, PERRIÈRE N, DENIS I, LAVIALLE M, GUESNET P: n-3 Fatty acids modulate brain glucose transport in endothelial cells of the blood-brain barrier. Prostaglandins Leukot Essent Fatty Acids 77: 279-286, 2007.

PLUTA RM: Dysfunction of nitric oxide synthases as a cause and therapeutic target in delayed cerebral vasospasm after SAH. Acta Neurochir 104: 139-147, 2008.

PLUTZKY J: Atherosclerotic plaque rupture: emerging insights and opportunities. Am J Cardiol 84: 15J-20J, 1999.

PURI BK, COUNSELL SJ, HAMILTON G, RICHARDSON AJ, HORROBIN DF: Eicosapentaenoic acid in treatmentresistant depression associated with symptom remission, structural brain changes and reduced neuronal phospholipid turnover. Int J Clin Pract 55: 560-563, 2001.

PURI BK: Cardiovascular disease and depression: the PUFA connection. Int J Clin Pract 62: 355-357, 2008.

RAATZ SK, REDMON JB, WIMMERGREN N, DONADIO JV, BIBUS DM: Enhanced absorption of n-3 fatty acids from emulsified compared with encapsulated fish oil. J Am Diet Assoc 109: 1076-1081, 2009.

REES D, MILES EA, BANERJEE T, WELLS SJ, ROYNETTE CE, WAHLE KW, CALDER PC: Dose-related effects of eicosapentaenoic acid on innate immune function in healthy humans: a comparison of young and older men. Am J Clin Nutr 83: 331-342, 2006.

RIZOS EC, ELISAF MS: Current evidence and future perspectives of omega-3 polyunsaturated fatty acids for the prevention of cardiovascular disease. Eur J Pharmacol 706: 1-3, 2013

ROGERS PJ, APPLETON KM, KESSLER D, PETERS TJ, GUNNELL D, HAYWARD RC, HEATHERLEY SV, CHRISTIAN LM, MCNAUGHTON SA, NESS AR: No effect of n-3 long-chain polyunsaturated fatty acid (EPA and DHA) supplementation on depressed mood and cognitive function: a randomised controlled trial. Br J Nutr 99: 421-431, 2008.

SAKABE M, SHIROSHITA-TAKESHITA A, MAGUY A, DUMESNIL C, NIGAM A, LEUNG TK, NATTEL S: Omega-3 polyunsaturated fatty acids prevent atrial fibrillation associated with heart failure but not atrial tachycardia remodeling. Circulation 116: 2101-2109, 2007.

SALEM N JR, PAWLOSKY R, WEGHER B, HIBBELN J: In vivo conversion of linoleic acid to arachidonic acid in human adults. Prostaglandins Leukot Essent Fatty Acids 60: 407-410, 1999.

SANCHEZ-VILLEGAS A, HENRÍQUEZ P, FIGUEIRAS A, ORTUÑO F, LAHORTIGA F, MARTÍNEZGONZÁLEZ MA: Long chain omega-3 fatty acids intake, fish consumption and mental disorders in the SUN cohort study. Eur J Nutr 46: 337-346, 2007.

SCOTT J: Pathophysiology and biochemistry of cardiovascular disease. Curr Opin Genet Dev 14: 271-279, 2004.

SERHAN CN: Novel eicosanoid and docosanoid mediators: resolvins, docosatrienes, and neuroprotectins. Curr Opin Clin Nutr Metab Care 8: 115-121, 2005.

SEVERUS WE, LITTMAN AB, STOLL AL: Omega-3 fatty acids, homocysteine, and the increased risk of cardiovascular mortality in major depressive disorder. Harv Rev Psychiatry 9: 280-293, 2001.

SHINOHARA M, MIRAKAJ V, SERHAN CN: Functional metabolomics reveals novel active products in the DHA metabolome. Front Immunol 3: 81, 2012.

SIMOPOULOS AP: The importance of the ratio of omega-6/omega-3 essential fatty acids. Biomed Pharmacother 56: 365-379, 2002

SINCLAIR HM: Deficiency of essential fatty acids and atherosclerosis, etcetera. Lancet 270: 381-383, 1956.

SKAABY T: The relationship of vitamin D status to risk of cardiovascular disease and mortality. Dan Med $J$ 62: B5008, 2015.

STAHL LA, BEGG DP, WEISINGER RS, SINCLAIR AJ: The role of omega-3 fatty acids in mood disorders. Curr Opin Investig Drugs 9: 57-64, 2008.

STAMLER JS, OSBORNE JA, JARAKI O, RABBANI LE, MULLINS M, SINGEL D, LOSCALZO J: Adverse vascular effects of homocysteine are modulated by endothelium-derived relaxing factor and related oxides of nitrogen. J Clin Invest 91: 308-318, 1993.

STILLWELL W, WASSALL SR: Docosahexaenoic acid: membrane properties of a unique fatty acid. Chem Phys Lipids 126: 1-27, 2003. 
STRØM M, MORTENSEN EL, HALLDORSSON TI, THORSDOTTIR I, OLSEN SF: Fish and long-chain n-3 polyunsaturated fatty acid intakes during pregnancy and risk of postpartum depression: a prospective study based on a large national birth cohort. Am J Clin Nutr 90: 149-155, 2009.

SUBLETTE ME, ELLIS SP, GEANT AL, MANN JJ: Meta-analysis of the effects of eicosapentaenoic acid (EPA) in clinical trials in depression. J Clin Psychiatry 72: 1577-1584, 2011.

SUBLETTE ME, MILAK MS, HIBBELN JR, FREED PJ, OQUENDO MA, MALONE KM, PARSEY RV, MANN JJ: Plasma polyunsaturated fatty acids and regional cerebral glucose metabolism in major depression. Prostaglandins Leukot Essent Fatty Acids 80: 57-64, 2009.

SUOMINEN-TAIPALE AL, PARTONEN T, TURUNEN AW, MÄNNISTÖ S, JULA A, VERKASALO PK: Fish consumption and omega-3 polyunsaturated fatty acids in relation to depressive episodes: a cross-sectional analysis. PLoS One 5: e10530, 2010.

TAVAZZI L, MAGGIONI AP, MARCHIOLI R, BARLERA S, FRANZOSI MG, LATINI R, LUCCI D, NICOLOSI GL, PORCU M, TOGNONI G, GISSI-HF INVESTIGATORS: Effect of n-3 polyunsaturated fatty acids in patients with chronic heart failure (the GISSI-HF trial): a randomised, double-blind, placebo-controlled trial. Lancet 372: 1223-1230, 2008.

THIES F, GARRY JM, YAQOOB P, RERKASEM K, WILLIAMS J, SHEARMAN CP, GALLAGHER PJ, CALDER PC, GRIMBLE RF: Association of n-3 polyunsaturated fatty acids with stability of atherosclerotic plaques: a randomised controlled trial. Lancet 361: 477-485, 2003.

TIWARI S, PRATYUSH DD, GUPTA SK, SINGH SK: Vitamin D deficiency is associated with inflammatory cytokine concentrations in patients with diabetic foot infection. Br J Nutr 112: 1938-1943, 2014.

TONHAJZEROVÁ I, ONDREJKA I: Depression in children and adolescents and its impact on the chronotropic regulation of cardiac function. (In Slovak) In: Depression. VAVRUŠOVÁ L et al. (eds), Osveta, Martin, 2008, pp 159-169.

TREBATICKÁ J, HRADEČNÁ Z, BOHMER F, VAVÁKOVÁ M, WACZULÍKOVÁ I, GARAIOVÁ I, LUHA J., ŠKODÁČEK I, ŠUBA J, ĎURAČKOVÁ Z: Omega-3 fatty acids in the form of fish oil emulsion modulate symptoms of depressive disorder in children and adolescents - a pilot study. Child Adolesc Psychiatry Ment Health: in press, 2017.

TRICHOPOULOU A, COSTACOU T, BAMIA C, TRICHOPOULOS D: Adherence to a Mediterranean diet and survival in a Greek population. N Engl J Med 348: 2599-2608, 2003.

VANCASSEL S, LEMAN S, HANONICK L, DENIS S, ROGER J, NOLLET M, BODARD S, KOUSIGNIAN I, BELZUNG C, CHALON S: n-3 polyunsaturated fatty acid supplementation reverses stress-induced modifications on brain monoamine levels in mice. J Lipid Res 49: 340-348, 2008.

VRABLÍK M, PRUSÍKOVÁ M, ŠNEJDRLOVÁ M, ZLATOHLÁVEK L: Omega-3 fatty acids and cardiovascular disease risk: Do we understand the relationship? Physiol Res 58: S19-S26, 2009.

WICHERS M, MAES M: The psychoneuroimmuno-pathophysiology of cytokine-induced depression in humans. Int J Neuropsychopharmacol 5: 375-388, 2002.

WILLEUMIER K, TAYLOR DV, AMEN DG: Decreased cerebral blood flow in the limbic and prefrontal cortex using SPECT imaging in a cohort of completed suicides. Transl Psychiatry 1: e28, 2011.

WORLD HEALTH ORGANIZATION: Prevention of cardiovascular disease. Guidelines for assessment and management of cardiovascular risk. World Health Organization, Geneva, 2007.

YAO JK, VAN KAMMEN DP: Red blood cell membrane dynamics in schizophrenia. I. Membrane fluidity. Schizophr Res 11: 209-216, 1994.

ZHU DM, LIU Y, ZHANG AG, CHU ZX, WU Q, LI H, GE JF, DONG Y, ZHU P: High levels of vitamin D in relation to reduced risk of schizophrenia with elevated C-reactive protein. Psychiatry Res 228: 565-570, 2015.

ZIMMER L, DELPAL S, GUILLOTEAU D, AÏOUN J, DURAND G, CHALON S: Chronic n-3 polyunsaturated fatty acid deficiency alters dopamine vesicle density in the rat frontal cortex. Neurosci Lett 284: 25-28, 2000.

ZIMMER L, HEMBERT S, DURAND G, BRETON P, GUILLOTEAU D, BESNARD JC, CHALON S: Chronic n-3 polyunsaturated fatty acid diet-deficiency acts on dopamine metabolism in the rat frontal cortex: a microdialysis study. Neurosci Lett 240: 177-181, 1998. 